\title{
BEAR MARKET PERIODS DURING THE 2007-2009 FINANCIAL CRISIS: DIRECT EVIDENCE FROM THE VISEGRAD COUNTRIES
}

\author{
Joanna OLBRYŚ - Elżbieta MAJEWSKA \\ (Received: 17 February 2014; revision received: 23 May 2014; \\ accepted: 8 August 2014)
}

\begin{abstract}
The main goal of this paper is a quantitative identification of bear market periods during the 20072009 global financial crisis in the case of the Visegrad Group stock markets. We analyse four countries, namely Poland, the Czech Republic, Hungary, and Slovakia and, for comparison, the US stock market. The sample period begins on May1, 2004, and ends on April 30, 2013, i.e. it includes the 2007 US subprime crisis. We use the statistical method of dividing market states into bullish and bearish markets. Our results reveal October 2007-February 2009 as the common downmarket period of the recent global financial crisis, except for Slovakia. It is instructive to formally identify crises, as it enables sensitivity analyses of various relationships and linkages among international stock markets using econometric and statistical tools, with respect to the pre-, post- and crisis periods. Moreover, we investigate the effect of increasing cross-market correlations in the crisis compared to the pre-crisis period, applying both standard contemporaneous correlations and volatility-adjusted correlation coefficients. The results confirm that accommodating heteroskedasticity is critical for detecting contagion across economies. A number of studies document that crossmarket correlations vary over time, thereby making the benefits of international portfolio choice and diversification questionable.
\end{abstract}

JEL classification indices: C10, F36, F44, G01, G15, O52

Keywords: Visegrad Group stock markets, crisis period, market states, cross-market correlations, contagion

Joanna Olbryś, corresponding author. Assistant Professor at the Department of Theoretical Computer Science, Faculty of Computer Science, Bialystok University of Technology, Poland.

E-mail: j.olbrys@pb.edu.pl

Elżbieta Majewska, Assistant Professor at the Institute of Mathematics, Faculty of Mathematics and Informatics, University of Bialystok, Poland. E-mail: elam@math.uwb.edu.pl 


\section{INTRODUCTION}

As argued by Southall (2008: 1), "Subsequent to the dismantling of the Soviet Union in the 1990s, improved political stability and reforms have substantially changed the economic environment in the Central and Eastern European economies". An event that had a significant impact on a group of eight Central and Eastern European (CEE) emerging markets was the accession to the European Union (EU) on May 1, 2004. Among others, four Visegrad countries (V-4, i.e. Poland, the Czech Republic, Hungary and Slovakia) were successful in the negotiations with the EU and they accessed the EU. The financial integration between the V-4 and developed markets has critical implications for stock market comovements. For this reason, the V-4 markets are particularly interesting in many respects, also in the context of the recent global financial crisis. Many researchers stress that given their varied histories, it is crucial to investigate and compare stock markets in the V-4 countries. It is worth recalling that formal stock markets were created in Poland and Hungary at the beginning of 1991. Exchanges in Warsaw and Budapest started with very few firms and adopted a process of applying regulations and listing requirements to provide for the expansion of the market. ${ }^{1}$ On the other hand, stock markets in the two parts of the former Czechoslovakia (i.e. the Czech Republic and Slovakia) were created in mid-1993, and they came about as a byproduct of voucher privatisation (Hanousek - Filer 2000: 624).

The main contribution of this paper is a quantitative identification of bear market periods on the V-4 stock markets and, for comparison, on the US stock market. The sample period begins with the Visegrad Group's accession to the EU on May 1, 2004, and ends on April 30, 2013, and it includes the 2007 US subprime crisis period. We use the method of dividing market states into bullish and bearish markets (Pagan - Sossounov 2003). This procedure enables the detection of cycles in equity prices. Our results reveal October 2007-February 2009 as the common down-market period during the 2007-2009 global financial crisis, except for Slovakia. The precise identification of market states, especially during the crisis, is crucial because of the many practical implications in the light of market globalisation as well as international portfolio choice and diversification. To the best of the authors' knowledge, no such research has been undertaken jointly for the Visegrad Group and the US stock markets.

1 After the re-establishment, the Warsaw Stock Exchange held its first trading session on April 16, 1991 with five listed companies, all of which were formerly state-owned companies that had been privatised. Similarly, on June 21, 1990, the Budapest Stock Exchange reopened its doors with only one single equity to trade - IBUSZ. 
Furthermore, we investigate the effect of increasing cross-market correlations in the crisis compared to the pre-crisis period in the context of contagion, applying both the standard contemporaneous cross-correlations and volatility-adjusted cross-correlation coefficients proposed by Forbes - Rigobon (2002), who stressed that market return volatility can bias standard cross-correlations. Our results directly confirm that accommodating heteroskedasticity is critical for detecting contagion across economies.

The remainder of this study is organised as follows. Section 2 presents a brief literature review concerning the US subprime crisis and its influence on the European markets. Section 3 specifies the methodological background of the statistical method of dividing market states into bullish and bearish markets. In Section 4 , we propose a brief analysis of the effect of increasing cross-market correlations in bear markets, especially in crisis periods. In Section 5, we present data description and empirical results on the main indexes of the V-4 and US stock markets. Section 6 covers the main findings and presents the conclusions.

\section{THE 2007 US SUBPRIME CRISIS - THE INFLUENCE ON THE EUROPEAN MARKETS}

According to the literature (e.g. Calomiris 2009; Brunnermeier 2009; Claessens et al. 2010), the financial crisis timeline, from the US perspective, was marked by the following events: (1) the increase in subprime delinquency rates in the spring of 2007, (2) the ensuing liquidity crunch in late 2007, (3) the liquidation of Bear Stearns in March 2008, and (4) the failure of Lehman Brothers in September 2008. The US economy officially slipped into a recession following the peak in December 2007. It is important to note that the crisis began in the US, but initially it did not fully and strongly affect the emerging markets. Claessens et al. (2010) identified five groups of countries based on the date they were affected by the crisis. They asserted that Hungary entered recession in 2008Q2, together with the major Western European countries, i.e. the UK, France and Germany, while Poland and the Czech Republic slipped into recession in 2008Q4. Slovakia entered recession with a delay, in 2009 Q1. It should be noted that the severity of the recent downturn was considerably smaller than elsewhere in the case of Poland. Poland was the only EU member state that showed real GDP growth in 2009. The resilience of the Polish economy was particularly conspicuous when compared to other V-4 countries, whose economies shrank to a similar extent as the EU-15 (Konopczak - Marczewski 2011). Marer (2010) analysed the impact of the crisis on the Eastern European economies, and he stressed that the global 
crisis hit Hungary immediately and hard, while Poland, the Czech Republic and Slovakia were less affected.

Unfortunately, there is no unanimity in determining the phases of the crisis among the researchers. For example, Pisani-Ferry - Sapir (2010) proposed two phases of the crisis in the EU. They advocated that the first phase started in August 2007 with a general liquidity strain. The second phase started in September 2008 with the bankruptcy of Lehman Brothers. Similarly, Mishkin (2011) divided the financial crisis into two distinct phases: the first from August 2007 to August 2008, called the US subprime mortgage crisis, and the second, which started in mid-September 2008, known as the global financial crisis. Frank - Hesse (2009) found that end-February 2007 was a period when early signs of stress began to emerge in global markets prior to the time when the subprime crisis was revealed in mid-2007. Dooley - Hutchison (2009) investigated the links between the US and a broad range of emerging markets over a subprime crisis period from February 2007 to March 2009. They analysed three phases of the subprime crisis and they argued that the first phase of the crisis ran from February 27, 2007. The authors stressed that emerging markets were somewhat insulated and decoupled from the US from early 2007 to summer 2008. Mun - Brooks (2012) extended Dooley and Hutchison's analysis to a broader set of developed and emerging markets, and also extended the whole sample period to February 2010. Kizys Pierdzioch (2011) studied the collapse of the three biggest Central and Eastern European markets (CEE-3), i.e. of Poland, the Czech Republic, and Hungary (except for Slovakia) during the recent financial crisis. They suggested that the most severe collapse in these markets occurred in November 2008, right after the collapse of Lehman Brothers. Specifically, during the last three months of 2008, the stock market indexes in Warsaw, Prague, and Budapest showed a clear tendency to decrease. Calomiris et al. (2012) considered three "crisis shocks" related to key features of the 2007-2008 crisis for the emerging and developed economies: the collapse of global trade, the contraction of credit supply, and selling pressure on firms' equity. They tested firms in the CEE-3 countries among other emerging markets. They advocated August 2007-December 2008 as the crisis period. Bartram - Bodnar (2009) proposed a detailed investigation of the global financial crisis 2008/2009 and provided a timeline of events and policy actions for the crisis in equity markets. They stressed that at the beginning of October 2007, world equity markets measured an all-time high USD market capitalisation of more than $\$ 51$ trillion as of this date, whereas by the end of February 2009 , global equity market capitalisation stood at just over $\$ 22$ trillion, that is, it dropped off more than 56\%. However, as the Lehman collapse on September 15, 2008 was a key event, they concluded that for their purposes the crisis period is defined as the close of the markets on Friday, September 12, 2008, to the close of 
trading on Monday, October 27, 2008. Moreover, they proposed January 1, $2007-$ September 12, 2008 as the pre-crisis period, and October 28, 2008-February 27 , 2009 as the post-crisis period. As a matter of fact, their choice of the post-crisis period seems to be rather controversial in the light of the stock market indexes continuing their decline during this period (cf. Figures 1-5). Olbryś - Majewska (2013) proposed February 27, 2007-March 9, 2009 as a crisis period, based on the S\&P500 index decline. The overall S\&P500 index fell from 1399.04 (February 27,2007 ) to 676.53 (March 9, 2009) and it lost $51.64 \%$ of its previous value during the crisis period.

\section{DIVIDING MARKET STATES}

Fabozzi - Francis (1977) pointed out that there is more than one definition of bull and bear markets. Therefore, they proposed three alternative definitions of bull and bear market conditions. The first categorisation was based on market trends. The second ignored market trends and viewed a market portfolio return every month independently. The third procedure divided the sample into three subsets: (1) months when the market moved up substantially, (2) months when the market moved down substantially, and (3) months when the market moved neither up nor down substantially. Substantial moves were arbitrarily defined as months when the absolute value of a market return was larger than half of one standard deviation of the market's returns measured over the total sampled period (Fabozzi Francis 1977). Also, Lunde - Timmermann (2000) stressed that there is no generally accepted formal definition of bull and bear markets in the finance literature. In one paper (Cooper et al. 2004), a bull ("up") or a bear (“down") market was identified when the past 12-, 24-, or 36-month market return was non-negative or negative, respectively. The identification of market states (in other words, of cycles in equity prices) is a problem of considerable importance, as Cooper et al. (2004), among others, found that profits to investment strategies depend critically on the state of the market.

Pagan - Sossounov (2003) developed an algorithm that seemed to be useful in locating periods in time that were considered bull and bear markets in US equity prices. They tested the monthly data of the New York market index (S\&P500) in the period from January 1835 to May 1997. Lee et al. (2011) proposed a modified version of the Pagan-Sossounov method of dividing market states into bullish, bearish, and range-bound markets. They analysed the Taiwanese market in the period January 1997-December 2007. They stressed that investors usually cannot identify the present market state, and that they often refer to past market states as they make investment decisions. Lunde - Timmermann (2000) created an algo- 
rithm for detecting bull and bear states. They investigated a new type of long-run dependence in stock prices based on the distribution of time spent in markets where cumulated returns exceed some positive threshold value (bull states), or fall below some negative threshold value (bear states).

We employ a three-stage procedure of dividing market states into bullish and bearish markets (Olbryś - Majewska 2014). Our methodology builds on Pagan - Sossounov (2003). The bullish (bearish) market state refers to a continuous uptrend (downtrend) in the market index. In the first step, we conduct a preliminary identification of turning points, i.e. peaks and troughs, based on the conditions (1)-(2), respectively:

$$
\begin{aligned}
& \ln P_{t-8}, \ldots, \ln P_{t-1}<\ln P_{t}>\ln P_{t+1}, \ldots, \ln P_{t+8} \\
& \ln P_{t-8}, \ldots, \ln P_{t-1}>\ln P_{t}<\ln P_{t+1}, \ldots, \ln P_{t+8}
\end{aligned}
$$

where $P_{t}$ represents the market index of month $t$, and from successive peaks/ troughs we choose the highest/deepest one, respectively. Pagan - Sossounov (2003) stressed that in the cycle literature, an algorithm for describing turning points in time series was developed by Bry - Boschan (1971), but they modified this algorithm by taking the eight months window (instead of six) in marking the initial location of turning points. The main goal was not to smooth any of the monthly, already smoothed, data.

In the second step, we exclude the phases (peak-trough or trough-peak) that last for less than four months, and cycles (peak-trough-peak or trough-peaktrough) that last for less than sixteen months. Pagan - Sossounov (2003) pointed out that in cycle dating, the minimal cycle length is fifteen months, hence sixteen months were chosen to create a symmetric window of eight periods. Furthermore, they advocated four months as the minimal length of a phase.

In the last step, we calculate the amplitudes $A$ for each phase (amplitude is the difference in the natural logs of the index value in subsequent turning points). During the bull/bear market period there must be a large enough (of at least 20\%) rise/fall in the index value (Pagan - Sossounov 2003: 26). This means that the amplitude of a given phase must fulfil the condition $A \geq 0.18$ or $A \leq-0.22$ for the bull or bear market period, respectively. Indeed, if a growth of the index value in an up-market period will equal at least $20 \%$, then

$$
A=\ln P_{t+1}-\ln P_{t}=\ln \frac{P_{t+1}}{P_{t}}>\ln \frac{1.2 \cdot P_{t}}{P_{t}}=\ln 1.2 \approx 0.18 .
$$


By analogy, if a decline of the index value in a down-market period will equal at least $20 \%$, then

$$
A=\ln P_{t+1}-\ln P_{t}=\ln \frac{P_{t+1}}{P_{t}}<\ln \frac{0.8 \cdot P_{t}}{P_{t}}=\ln 0.8 \approx-0.22 .
$$

\section{THE EFFECT OF INCREASING CROSS-MARKET CORRELATIONS IN THE CRISIS PERIOD}

International equity market correlation is a very important topic because of many practical implications, especially in the context of international portfolio diversification. "Typically, portfolio diversification is achieved using two main strategies: investing in different classes of assets thought to have little of negative correlation or investing in similar classes of assets in multiple markets through international diversification. While these two strategies have solid theoretical justification and strong empirical evidence exists as to the benefits, investors must be aware that correlation is dynamic and varies over time, changing the amount of portfolio diversification within a given asset allocation. In particular, a number of studies document that correlation between equity returns increases during bear markets and decreases when stock exchanges rally" (Cappiello et al. 2006: 7). Longin Solnik (2001) studied the conditional correlation structure of international equity returns and derived a formal statistical method, based on the extreme value theory. They investigated monthly equity index returns for five countries: the US, the UK, France, Germany, and Japan, in the period January 1959-December 1996. They found that conditional correlation increases in bear markets, but not in bull markets. Based on data for international equity markets (i.e. the US, the UK, France, and Germany), and major stock market indexes in the period from May 1990 to December 1999, Campbell et al. (2002) found evidence of significant increased correlation in international equity returns in bear markets. Goetzmann et al. (2005) examined the correlation structure of the major world markets over 150 years. They found that international equity correlations change dramatically through time, thus the diversification benefits to global investing are not constant. Hong et al. (2007) provided a model-free test for asymmetric correlations in bear versus bull markets. They evaluated the economic significance of incorporating asymmetries into investment decisions.

Although there is no unanimity in research regarding the reasons of increasing cross-market correlations in crisis periods, the majority of researchers agree that correlations change dramatically during crucial market events. This evidence is often justified by the authors as the consequence of contagion (e.g. Bekaert et 
al. 2005; Kizys - Pierdzioch 2011). On the other hand, Forbes - Rigobon (2002) showed that correlation coefficients are conditional on market volatility. As a result, during a crisis, when stock market volatility increases, estimates of crossmarket correlations will be biased upward. The authors analysed international markets in the context of contagion, but they found that there was no increase in unconditional correlation coefficients (i.e. no contagion) during the 1997 Asian crisis, the 1994 Mexican devaluation, and the 1987 US market crash. As a matter of fact, contagion is not simply revealed by increased correlation of market returns during a crisis period (e.g. Edwards 2000; Bekaert et al. 2005) and references therein. As Bekaert et al. (2005: 39-40) pointed out, one of the most interesting aspects of the contagion debate is the disagreement over a precise definition. They defined contagion as excess correlation, that is, correlation over and above what one would expect from economic fundamentals. Edwards (2000) presented some important stylised facts concerning contagion. Among others, Rigobon (2002: 4) stressed that "there is no accordance on what contagion means". Furthermore, Forbes - Rigobon (2002) defined contagion as a significant increase in cross-market linkages after a shock to one country (or group of countries), but they stated that this definition is not universally accepted. They stressed that heteroskedasticity in market returns biases tests for contagion based on correlation. The authors proposed the following correction for the volatility bias:

$$
\hat{\rho}_{V A}=\frac{\hat{\rho}_{C}}{\sqrt{1+\delta\left[1-\left(\hat{\rho}_{C}\right)^{2}\right]}},
$$

where $\hat{\rho}_{V A}$ is the unconditional volatility-adjusted cross-correlation coefficient between markets, $\hat{\rho}_{C}$ is the estimated conditional cross-correlation coefficient in the crisis period, and $\delta$ is the relative increase in the variance of market returns in the crisis period compared to the pre-crisis period:

$$
\delta=\frac{\hat{\sigma}_{C}^{2}}{\hat{\sigma}_{P C}^{2}}-1,
$$

where $\hat{\sigma}_{C}^{2}, \hat{\sigma}_{P C}^{2}$ are the variances in the high-volatility (crisis) and low-volatility (pre-crisis) periods, respectively. By construction, it is obvious that $\hat{\sigma}_{C}^{2} \geq \hat{\sigma}_{P C}^{2}$, hence $\delta \geq 0$ and $\hat{\rho}_{V A} \leq \hat{\rho}_{C}$, that is, during the periods of high volatility, the unconditional volatility-adjusted cross-correlation $\hat{\rho}_{V A}$ will be smaller than the estimated conditional cross-correlation $\hat{\rho}_{C}$ between markets. The evaluation of contagion is carried out by testing the hypotheses:

$$
\begin{aligned}
& H_{0}: \rho_{V A}=\rho_{P C} \\
& H_{1}: \rho_{V A}>\rho_{P C}
\end{aligned}
$$


where $\rho_{P C}$ is the cross-correlation coefficient in the pre-crisis period, and the null hypothesis states that there is no contagion. The $Z$-statistic, which is asymptotically a standard normal random variable, tests the null of no contagion, that is, the equality of the crisis with pre-crisis cross-market correlation coefficients (Southall 2008: 47). The test is performed with the Fisher (1921) $z$-transformation of sample correlation coefficients. If the value of the $Z$-statistic is greater than the critical value, the null hypothesis of identical correlation coefficients can be rejected.

It is worthwhile to note that according to the literature, some researchers explain the changing nature of correlations between international markets over the evolution of the global financial crisis in terms of the influence of news, and they often employ the "event study" or similar methodology (e.g. Bartram - Bodnar 2009; Dooley - Hutchison 2009; Mun - Brooks 2012). For example, Mun - Brooks (2012) explored the relative roles of news and volatility in explaining the changes in correlations between national stock markets during the global 2007-2008 financial crisis. Their analysis focused on the changing nature of correlations across four distinct phases of the global financial crisis.

\section{DATA DESCRIPTION AND EMPIRICAL RESULTS ON THE MAIN INDEXES OF THE VISEGRAD GROUP AND US STOCK MARKETS}

As mentioned earlier, four Visegrad countries among eight emerging markets were successful in the negotiations with the EU and they accessed the EU on May 1, 2004. These four Visegrad countries, in order of decreasing population size are: Poland, the Czech Republic, Hungary and Slovakia. The data consists of monthly logarithmic returns of the major V-4 stock market indexes (WIG, PX, BUX, and SAX), and the New York market index (S\&P500). There are 108 monthly observations for each series for the period beginning May 2004 and ending April 2013 (nine years). All analyses are conducted using the open-source computer software Gretl 1.9.14 (Adkins 2013).

\subsection{Preliminary statistics}

Table 1 presents brief information about the major Visegrad Group stock market indexes, in order of decreasing value of market capitalisation at the end of 2012.

Table 2 reports summarised statistics for the monthly logarithmic returns for five stock indexes: S\&P500, WIG, PX, BUX, and SAX, as well as statistics testing for normality and interdependence. 
Table 1. The major Visegrad Group stock market indexes used in the study

\begin{tabular}{l|l|c|l|l}
\hline & Market & $\begin{array}{c}\text { Market Cap., } \\
\text { EUR billion, } \\
\text { Dec. 2012 }\end{array}$ & Index & Some details of the index construction \\
\hline 1 & Warsaw & 134.8 & WIG & $\begin{array}{l}\text { The Warsaw Stock Exchange weighted index with rela- } \\
\text { tive weights based on the capitalisation of listed shares. } \\
\text { It contains all listed companies, except companies with } \\
\text { free-float below 10\%. }\end{array}$ \\
\hline 3 & Prague & 28.2 & PX & $\begin{array}{l}\text { The Prague Stock Exchange price index of blue-chip } \\
\text { issues, weighted by market capitalisation. }\end{array}$ \\
\hline 4 & Bratislava & 4.1 & SAX & $\begin{array}{l}\text { The official index of blue-chip shares listed on the Buda- } \\
\text { pest Stock Exchange. It is calculated based on the actual } \\
\text { market prices of a basket of shares. It is an index with } \\
\text { market capitalisation weighting corrected for free-float. }\end{array}$ \\
\hline
\end{tabular}

Source: http://www.gpw.pl/; http://www.pse.cz/; http://bse.hu/; http://www.bsse.sk/; http://fese.eu/en/; http:// www.world-exchanges.org

Table 2. Summarised statistics for monthly logarithmic returns for five stock indexes

\begin{tabular}{l|c|c|c|c|c|c|c}
\hline Index & Mean & $\begin{array}{c}\text { Standard } \\
\text { deviation }\end{array}$ & Skewness & $\begin{array}{c}\text { Excess } \\
\text { kurtosis }\end{array}$ & Doornik-Hansen test & LB(5) & LB $^{2}(5)$ \\
\hline S\&P500 & 0.003 & 0.044 & $\begin{array}{c}-1.05 \\
{[0.00]}\end{array}$ & $\begin{array}{c}2.55 \\
{[0.00]}\end{array}$ & $\begin{array}{c}16.18 \\
{[0.00]}\end{array}$ & $\begin{array}{c}13.84 \\
{[0.02]}\end{array}$ & $\begin{array}{c}37.90 \\
{[0.00]}\end{array}$ \\
\hline WIG & 0.006 & 0.065 & $\begin{array}{c}-0.72 \\
{[0.00]}\end{array}$ & $\begin{array}{c}2.56 \\
{[0.00]}\end{array}$ & $\begin{array}{c}16.62 \\
{[0.00]}\end{array}$ & $\begin{array}{c}14.29 \\
{[0.01]}\end{array}$ & $\begin{array}{c}5.96 \\
{[0.31]}\end{array}$ \\
\hline PX & 0.002 & 0.070 & $\begin{array}{c}-1.24 \\
{[0.00]}\end{array}$ & $\begin{array}{c}4.12 \\
{[0.00]}\end{array}$ & $\begin{array}{c}21.79 \\
{[0.00]}\end{array}$ & $\begin{array}{c}14.54 \\
{[0.01]}\end{array}$ & $\begin{array}{c}25.95 \\
{[0.00]}\end{array}$ \\
\hline \multirow{2}{*}{ BUX } & 0.005 & 0.075 & $\begin{array}{c}-0.94 \\
{[0.00]}\end{array}$ & $\begin{array}{c}2.82 \\
{[0.00]}\end{array}$ & $\begin{array}{c}16.27 \\
{[0.00]}\end{array}$ & $\begin{array}{c}7.40 \\
{[0.19]}\end{array}$ & $\begin{array}{c}2.50 \\
{[0.78]}\end{array}$ \\
\hline SAX & 0.001 & 0.057 & $\begin{array}{c}0.86 \\
{[0.00]}\end{array}$ & $\begin{array}{c}6.54 \\
{[0.00]}\end{array}$ & $\begin{array}{c}61.23 \\
{[0.00]}\end{array}$ & $\begin{array}{c}24.45 \\
{[0.00]}\end{array}$ & $\begin{array}{c}7.57 \\
{[0.18]}\end{array}$ \\
\hline
\end{tabular}

Notes: Based on all sample observations during the period May 2004-April 2013.

The test statistic for skewness and excess kurtosis is the conventional t-statistic. The Doornik-Hansen test (2008) has a $\chi^{2}$ distribution if the null hypothesis of normality is true. Numbers in brackets are $p$-values. LB(q) and $\mathrm{LB}^{2}(\mathrm{q})$ are the Ljung - Box (1978) statistics for returns and squared returns, respectively, distributed as $\chi^{2}$ ( $q), q \approx \ln T$, where $T=108$ is the number of data points. The $\chi^{2}(5)$ critical value is $11.07(5 \%)$.

Source: Authors' calculations (using Gretl 1.9.14 software). 
Several results in Table 2 are worth special notice. The sample means are not statistically different from zero. The measure for skewness shows that all return series are skewed, and the measure for excess kurtosis shows that all series are highly leptokurtic with respect to the normal distribution. The Doornik-Hansen (2008) test rejects normality for each of the return series at the $5 \%$ level of significance. The Ljung-Box (1978) statistic at the $\operatorname{lag} q \approx \ln T$, where $T$ is the number of data points (Tsay 2010), calculated for both the return and the squared return series, indicates the presence of significant linear dependencies only in the case of the BUX series. The hypothesis of non-linear dependencies is rejected in the case of the S\&P500 and PX series.

\subsection{Bear market periods during the 2007-2009 financial crisis in the Visegrad Group and the US stock markets}

We employ the procedure of dividing market states into bullish and bearish markets to identify crisis periods on the stock exchanges. Figures 1-5 present the crisis periods for the S\&P500 and the V-4 stock market indexes obtained from the three-stage procedure described in Section 2. The empirical results are generated in the whole sample period from May 2004 to April 2013. The horizontal axis stands for time (months), and the vertical axis stands for the market index. Vertical lines and light grey areas stand for crisis periods.

As it is necessary to appoint one month as the beginning of the global crisis period for all countries, we propose October 2007. In the light of our results, it seems that we can treat February 2009 as the end of the global crisis period, which is consistent with Dooley - Hutchison's (2009) results, among others. Finally, we propose October 2007-February 2009 as the common period of the recent global financial crisis for the US and the CEE-3 countries (see Figures 1-4).

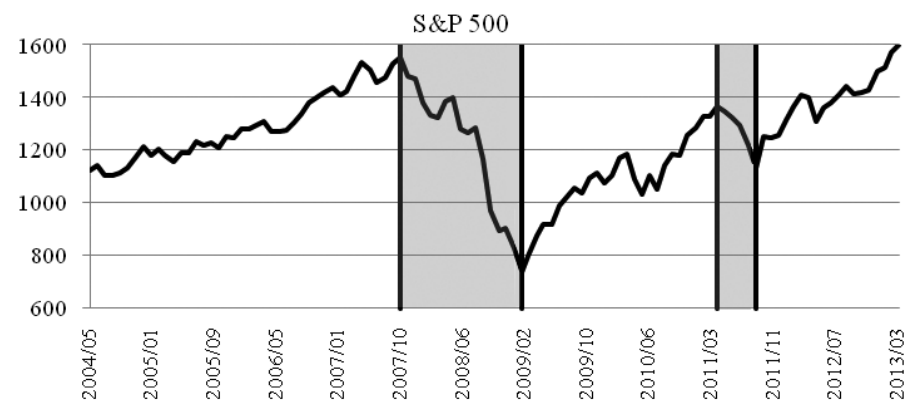

Figure 1. S\&P500 index (New York) 


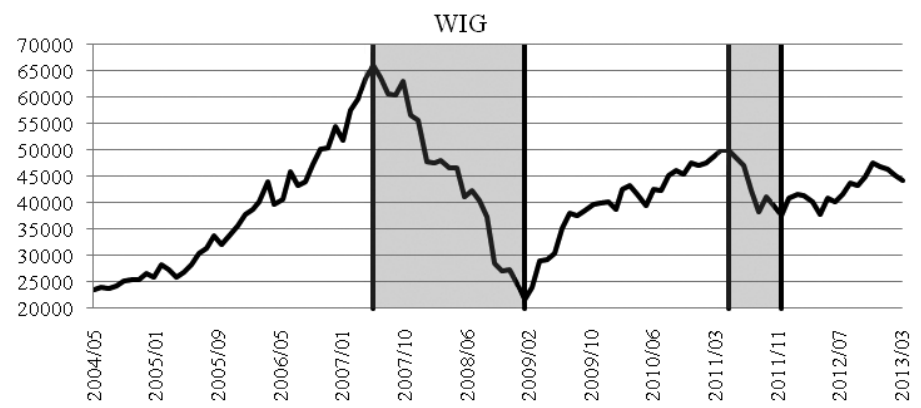

Figure 2. WIG index (Warsaw)

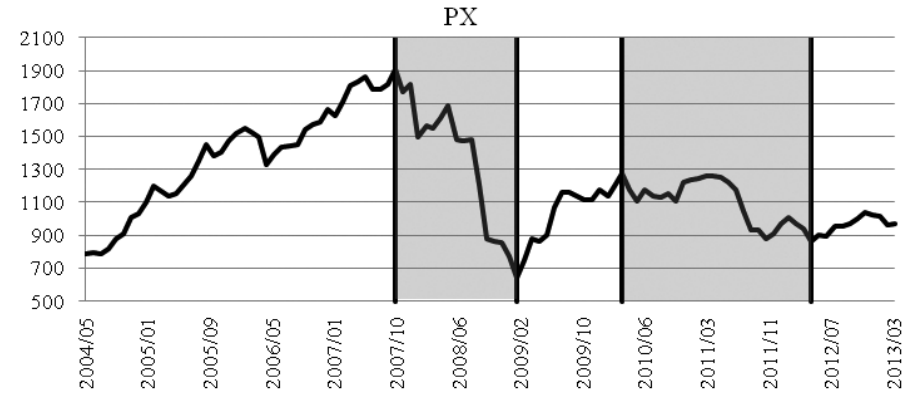

Figure 3. PX index (Prague)

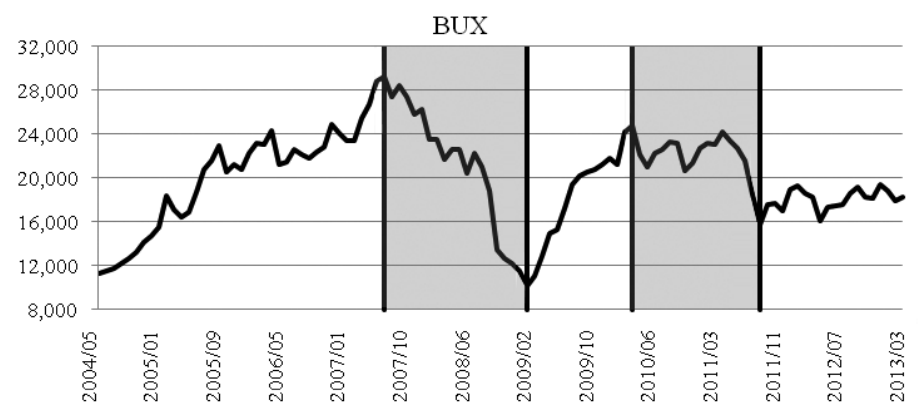

Figure 4. BUX index (Budapest) 


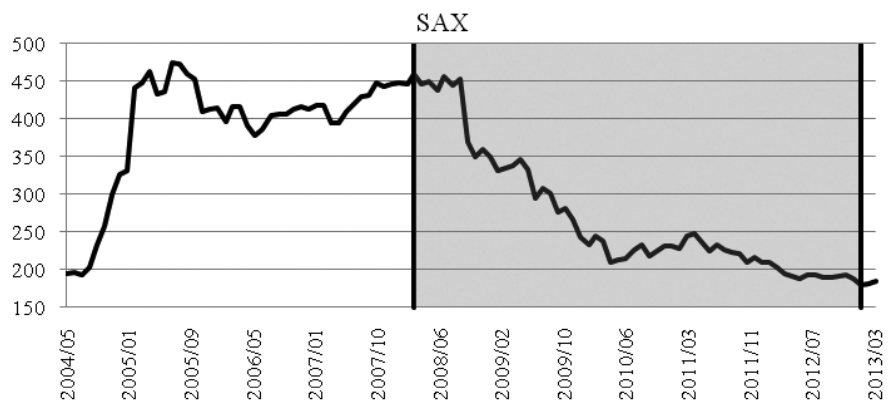

Figure 5. SAX index (Bratislava)

Notes: Figures 1-5 present crisis periods and down-markets for the S\&P500 and the V-4 stock market indexes obtained from the three-stage procedure of dividing market states, in the whole sample period May 2004-April 2013. The horizontal axis stands for time (months), and the vertical axis stands for the market index. Vertical lines and light grey areas stand for crisis periods or down-markets.

Only in the case of Slovakia (Figure 5) can we observe a pronounced delay of crisis symptoms. However, it is not surprising if we take into account that the Slovakian stock market is the smallest in the group. Smith (2009) stressed that European emerging stock markets can be usefully classified into three groups: (1) Russia, (2) four medium-size markets: the Czech Republic, Hungary, Poland and Turkey, (3) a group of 19 small, new markets, including Slovakia. Furthermore, the evidence is that for Slovakia, which accessed the euro area in January 1,2009, the crisis period is much longer and it includes the recent euro area crisis. According to the literature, a balance-of-payments and a fiscal crisis within the EMU started in Spring 2010 (e.g. Merler - Pisani-Ferry 2012).

Moreover, we identify the following additional down-market periods in the sample investigated (cf. Figures 1-4): (1) the period April 2011-September 2011 for the S\&P500 index ( $\downarrow 17.0 \%)$; (2) the period May 2011-Dec 2011 for the WIG index ( $\downarrow 24.8 \%$ ); (3) the period April 2010-May 2012 for the PX index $(\downarrow 32.2 \%)$, and (4) the period April 2010-September 2011 for the BUX index $(\downarrow 36.3 \%)$. In our opinion, while the mentioned additional bear market period on the New York Stock Exchange was certainly not connected with the euro area crisis, we have some doubts in the case of Prague and Budapest. Although the Czech Republic and Hungary are not EMU countries, April 2010 is accepted in the literature as the beginning of the euro zone crisis period (e.g. Merler Pisani-Ferry 2012, among others). Hence, it is very likely that the subsequent down-market periods for Prague and Budapest were connected with the euro zone crisis (see Figures 3-4). 


\subsection{Correctness analysis}

We employ two methods for checking the bear market conditions, proposed by Fabozzi - Francis (1977): (1) the substantial moves procedure, and (2) the upand down-market procedure.

As for the first procedure, we obtained that during the down-market months the absolute value of expected market return was larger than half of one standard deviation of the stock market returns measured over the total sampled period, for all markets investigated. In the case of the S\&P500 index, the absolute value of the expected return $|-0.043|$ was even almost equal to the standard deviation 0.044 . According to the second procedure, the expected index returns were negative during the crisis periods for all stock markets investigated. Therefore, the determined periods were placed in the down category. Finally, the empirical results of both procedures confirmed the bear market periods presented in Figures 1-5.

\subsection{Contemporaneous and volatility-adjusted cross-market correlations}

As noted in Section 4, the evidence of significant increased correlation in international equity markets in bear market periods is well documented. Our goal is to confirm this observation during the recent 2007 US subprime crisis period for the V-4 and the US stock markets. We advocate October 2007-February 2009 as the common period of the recent global financial crisis, except for Slovakia.

The most important results are presented in Table 3, which contains standard contemporaneous cross-correlations and volatility-adjusted cross-correlation coefficients, given by Eq. (3) of monthly logarithmic returns on pairs of the indexes S\&P500/V-4 stock market index (excluding SAX). For comparison, we calculate dependencies both in the whole sample (May 2004-April 2013) and in two subsamples of equal size: (1) the pre-crisis period May 2006-September 2007 (17 months), and (2) the common crisis period October 2007-February 2009 (17 months). We investigate the cross-market linkages after a shock to the US financial market. Supporting values are equal to $\hat{\sigma}_{P C}^{2}=0.00362$ (the variance in the high-volatility period in the US stock market) and $\hat{\sigma}_{P C}^{2}=0.00053$ (the variance in the low-volatility period in the US stock market), while the relative increase in the variance of S\&P500, given by Eq. (4), is equal to $\delta=5.8663$. Our results confirm that during the period of high volatility in the US stock market (the common crisis period October 2007-February 2009), the estimated conditional crosscorrelations between the US and CEE-3 markets were substantially greater than the unconditional volatility-adjusted correlations, given by Eq. (3). 
Table 3. Contemporaneous cross-correlations and volatility-adjusted cross-correlations of monthly logarithmic returns on pairs S\&P500/V-4 stock market index (excluding SAX)

\begin{tabular}{|c|c|c|c|c|c|c|c|c|c|c|c|}
\hline & \multirow{3}{*}{ Index } & \multicolumn{6}{|c|}{ Contemporaneous cross-correlations } & \multicolumn{4}{|c|}{$\begin{array}{l}\text { Volatility-adjusted cross- } \\
\text { correlations }\end{array}$} \\
\hline & & $\begin{array}{l}\text { Whole } \\
\text { sample }\end{array}$ & $\begin{array}{l}\text { Pre- } \\
\text { crisis }\end{array}$ & \multicolumn{4}{|c|}{ Crisis (3) } & \multicolumn{4}{|c|}{ Crisis (3) } \\
\hline & & $\hat{\rho}$ & $\hat{\rho}_{P C}$ & $\hat{\rho}_{C}$ & $\begin{array}{l}\text { Increase } \\
\text { compared } \\
\text { to the } \\
\text { period (2) }\end{array}$ & 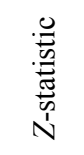 & 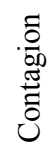 & $\hat{\rho}_{P A}$ & $\begin{array}{l}\text { Increase } \\
\text { compared } \\
\text { to the } \\
\text { period (2) }\end{array}$ & 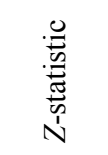 & 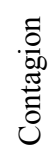 \\
\hline 1 & WIG & \begin{tabular}{|c|}
0.767 \\
{$[0.000]$}
\end{tabular} & $\begin{array}{c}0.438 \\
{[0.079]}\end{array}$ & $\begin{array}{c}0.850 \\
{[0.000]}\end{array}$ & $\uparrow 94.1 \%$ & 2.081 & $H_{1}$ & 0.524 & $\uparrow 19.7 \%$ & 0.298 & $H_{0}$ \\
\hline 2 & PX & $\begin{array}{c}0.750 \\
{[0.000]}\end{array}$ & $\begin{array}{c}0.672 \\
{[0.003]}\end{array}$ & $\begin{array}{c}0.894 \\
{[0.000]}\end{array}$ & $\uparrow 33.0 \%$ & 1.659 & $H_{1}$ & 0.606 & $\uparrow 9.9 \%$ & -0.297 & $H_{0}$ \\
\hline 3 & BUX & $\begin{array}{c}0.744 \\
{[0.000]}\end{array}$ & $\begin{array}{c}0.405 \\
{[0.107]}\end{array}$ & $\begin{array}{c}0.817 \\
{[0.000]}\end{array}$ & $\uparrow 101.7 \%$ & 1.900 & $H_{1}$ & 0.476 & $\uparrow 17.4 \%$ & 0.232 & $H_{0}$ \\
\hline
\end{tabular}

Notes: The table is based on: (1) the whole sample period May 2004-April 2013; (2) the pre-crisis period May 2006-September 2007 (17 months); (3) the common crisis period October 2007-February 2009 (17 months). The table contains contemporaneous correlation coefficients as well as volatility-adjusted cross-correlation coefficient $\hat{\rho}_{P A}$, given by Eq. (3), $p$-values are in brackets. Fisher's Z-statistic (1921) tests the null of no contagion. The Student's $t$ critical value is 1.3125 (at the $10 \%$ significance level).

Source: Authors' calculations (using Gretl 1.9.14 software).

Several results in Table 3 are especially important. In the case of contemporaneous cross-market correlations, the test based on the $Z$-statistic rejects the null of no contagion in the crisis period for each of the return series, at the $10 \%$ level of significance. The Student's $t$ critical value is 1.3125 in this case. However, there is no reason to reject the null hypothesis for volatility-adjusted cross-market correlations (the last column in Table 3). It means that the Forbes-Rigobon correction for heteroskedastic bias in index returns leads to substantial reduction in differences among cross-market correlation coefficients in both periods, and the conclusions concerning contagion effect are completely different. The correlation coefficients show that contagion is significant in all economies when within-sample heteroskedasticity is ignored. Our results are consistent with those of Forbes - Rigobon (2002) among others and confirm that accommodating heteroskedasticity is crucial for detecting contagion across international stock markets.

Table 4 reports standard contemporaneous cross-correlations of monthly logarithmic returns on pairs of the CEE-3 stock market indexes. As in Table 3, we calculate dependencies both in the whole sample (May 2004-April 2013) and 
Table 4. Contemporaneous cross-correlations of monthly logarithmic returns on pairs of the CEE-3 stock market indexes

\begin{tabular}{|c|c|c|c|c|c|c|c|}
\hline & Period & \multicolumn{2}{|c|}{ WIG/PX } & \multicolumn{2}{|c|}{ WIG/BUX } & \multicolumn{2}{|c|}{ PX/BUX } \\
\hline 1 & $\begin{array}{l}\text { Whole sample } \\
\text { May 2004-April } 2013\end{array}$ & \multicolumn{2}{|c|}{$\begin{array}{c}0.843 \\
{[0.000]}\end{array}$} & \multicolumn{2}{|c|}{$\begin{array}{c}0.804 \\
{[0.000]}\end{array}$} & \multicolumn{2}{|c|}{$\begin{array}{c}0.783 \\
{[0.000]} \\
\end{array}$} \\
\hline 2 & $\begin{array}{l}\text { Pre-crisis period } \\
\text { May 2006-September } 2007\end{array}$ & $\begin{array}{c}0.794 \\
{[0.000]}\end{array}$ & \multirow{2}{*}{$\uparrow 14.2 \%$} & $\begin{array}{c}0.591 \\
{[0.012]}\end{array}$ & \multirow{2}{*}{$\uparrow 44.5 \%$} & $\begin{array}{c}0.642 \\
{[0.006]}\end{array}$ & \multirow{2}{*}{$\uparrow 31.6 \%$} \\
\hline 3 & $\begin{array}{l}\text { Common crisis period } \\
\text { October 2007-February } 2009\end{array}$ & $\begin{array}{c}0.907 \\
{[0.000]}\end{array}$ & & $\begin{array}{c}0.854 \\
{[0.000]}\end{array}$ & & $\begin{array}{c}0.845 \\
{[0.000]}\end{array}$ & \\
\hline
\end{tabular}

Notes: The table is based on: (1) the whole sample period May 2004-April 2013; (2) the pre-crisis period May 2006-September 2007 (17 months); (3) the common crisis period October 2007-February 2009 (17 months). The table contains contemporaneous correlation coefficients and $p$-values in brackets.

Source: Authors' calculations (using Gretl 1.9.14 software)

Table 5. Contemporaneous cross-correlations of monthly logarithmic returns on pairs S\&P500/ V-4 stock market index (including SAX)

\begin{tabular}{c|c|c|c|c}
\hline & S\&P500/WIG & S\&P500/PX & S\&P500/BUX & S\&P500/SAX \\
\hline \multirow{3}{*}{ Period } & June 2007-February & October 2007- & July 2007-February & March 2008- \\
& 2009 & February 2009 & 2009 & February 2013 \\
& $(21$ months) & $(17$ months $)$ & $(20$ months $)$ & (60 months) \\
\hline \multirow{2}{*}{$\hat{\rho}$} & 0.822 & 0.894 & 0.798 & 0.389 \\
& {$[0.000]$} & {$[0.000]$} & {$[0.000]$} & {$[0.002]$} \\
\hline
\end{tabular}

Notes: The table is based on the bear market periods for each stock market investigated separately, according to Figures 2-5. The table contains contemporaneous correlation coefficients and $p$-values in brackets.

Source: Authors' calculations (using Gretl 1.9.14 software).

in two subsamples of equal size: (1) the pre-crisis period May 2006-September 2007, and (2) the common crisis period October 2007-February 2009. As we can observe in Table 4, there was an increase in cross-market contemporaneous correlations during the common crisis period October 2007-February 2009 compared to the pre-crisis period.

Table 5 presents standard contemporaneous cross-correlations of monthly logarithmic returns on S\&P500/V-4 stock market index pairs within the bear market phases identified for each particular market, not for the common period. Therefore, the Slovak stock market is investigated as well. The main evidence is that correlation coefficients are statistically significant in all cases, but for the S\&P500/SAX pair, the value of the coefficient is the lowest one. 


\section{CONCLUSION}

The purpose of this paper was a formal statistical identification of bear market periods during the 2007-2009 global financial crisis. We analysed the V-4 markets and, for comparison, the US stock market. The period investigated (May 2004-April 2013) includes the 2007 US subprime crisis period. We use the Pagan - Sossounov (2003) methodology of dividing market states into bullish and bearish markets, and our results reveal October 2007-February 2009 as the common down-market period of the recent financial crisis on the stock markets in the US, Poland, the Czech Republic and Hungary (i.e. CEE-3 countries). Only in the case of Slovakia can we observe a pronounced delay of crisis symptoms. However, it is not surprising, given that the Slovakian market is in the group of the smallest European stock markets. Furthermore, the evidence is that for Slovakia, which accessed the euro area on January 1, 2009, the crisis period is much longer and it includes the recent euro area crisis. Moreover, we identify additional down-market periods in the sample investigated for the CEE-3 and US stock markets. To sum up, the procedure seems to be useful in locating bear market periods in time.

The precise identification of market states (in other words, cycles in equity prices) is certainly important in practice, as many researchers found that profits to investment strategies depend critically on the state of the market. Unfortunately, due to the global nature of the crisis causes, diversification provided little help to investors when needed most, as markets dropped in tandem (Bartram - Bodnar 2009). Moreover, it is instructive to formally identify crises, as it enables the examination of various relationships and linkages among international stock markets, taking into consideration the pre-, post-, and crisis periods. According to the empirical finance literature, it is important to verify to what extent the results obtained during research depend on the choice of the period investigated. As a matter of fact, researchers quite often establish the pre-, post-, and crisis periods arbitrarily. Due to the importance of the problem, a possible direction for further investigation would be to identify market states applying other methods, for example, a Markov-switching model approach (Maheu - McCurdy 2000).

Our empirical findings confirm significant and high cross-market contemporaneous correlations during the common down-market period October 2007-February 2009. Moreover, we show that the correlation structure between the US and the V-4 stock markets is time-varying, especially during crises. We identify a statistically significant increase in cross-market contemporaneous correlations during the common crisis period compared to the pre-crisis period. However, the correlation coefficients show that contagion is significant in all economies when within-sample heteroskedasticity is ignored, but the Forbes - Rigobon's (2002) correction for heteroskedastic bias in index returns leads to a substantial reduction in differences 
among cross-market correlations in both periods. Hence, the conclusions concerning the contagion effect are substantially different. Our results directly confirm that accommodating heteroskedasticity is crucial for detecting contagion across economies. It is worthwhile to emphasise that high and asymmetric cross-market correlations have important negative aspects because of their practical implications in the light of market globalisation. First, they thwart investors' striving for international portfolio diversification in crises. Second, the asymmetry effect, i.e. significant increase in international cross-correlations in bear markets, additionally makes portfolio diversification especially difficult and questionable.

\section{REFERENCES}

Adkins, L. C. (2013): Using Gretl for Principles of Econometrics, 4th ed., Version 1.041. Oklahoma State University.

Bartram, S. M. - Bodnar, G. (2009): No Place to Hide: The Global Crisis in Equity Markets in 2008/2009. Journal of International Money and Finance, 28(8): 1246-1292.

Bekaert, G. - Harvey, C. R. - Ng, A. (2005): Market Integration and Contagion. Journal of Business, 78(1): 39-69.

Brunnermeier, M. K. (2009): Deciphering the Liquidity and Credit Crunch 2007-2008. Journal of Economic Perspectives, 23(1): 77-100.

Bry, G. - Boschan, C. (1971): Cyclical Analysis of Time Series: Selected Procedures and Computer Programs. New York: NBER.

Calomiris, C. W. (2009): The Subprime Turmoil: What's Old, What's New, and What's Next. Journal of Structured Finance, 15(1): 6-52.

Calomiris, C. W. - Love, J. - Martinez Peria, M. S. (2012): Stock Returns' Sensitivities to Crisis Shocks: Evidence from Developed and Emerging Markets. Journal of International Money and Finance, 31(4): 743-765.

Campbell, J.Y. - Koedijk, K. - Kofman, P. (2002): Increased Correlation in Bear Markets. Financial Analysts Journal, 58(1): 87-94.

Cappiello, L. - Engle, R. F. - Sheppard, K. (2006): Asymmetric Dynamics in the Correlations of Global Equity and Bond Returns. Journal of Financial Econometrics, 4(4): 537-572.

Claessens, S. - Dell'Ariccia, G. - Igan, D. - Laeven, L. (2010): Cross-Country Experience and Policy Implications from the Global Financial Crisis. Economic Policy, 25(62): 267-293.

Cooper, M. J. - Gutierrez, R. C. Jr. - Hameed, A. (2004): Market States and Momentum. Journal of Finance, 59(3): 1345-1365.

Dooley, M. - Hutchison, M. (2009): Transmission of the U.S. Subprime Crisis to Emerging Markets: Evidence on the Decoupling-Recoupling Hypothesis. Journal of International Money and Finance, 28(8): 1331-1349.

Doornik, J. A. - Hansen, H. (2008): An Omnibus Test for Univariate and Multivariate Normality. Oxford Bulletin of Economics and Statistics, 70, Supplement 1: 927-939.

Edwards, S. (2000): Contagion. World Economy, 23(7): 873-900.

Fabozzi, F. J. - Francis, J. C. (1977): Stability Tests for Alphas and Betas over Bull and Bear Market Conditions. Journal of Finance, 32(4): 1093-1099.

Fisher, R. A. (1921): On the "Probable Error" of a Coefficient of Correlation Deduced from a Small Sample. Metron, 1: 3-32. 
Forbes, K. J. - Rigobon, R. (2002): No Contagion, Only Interdependence: Measuring Stock Market Co-Movements. Journal of Finance, 57(5): 2223-2261.

Frank, N. - Hesse, H. (2009): Financial Spillovers to Emerging Markets during the Global Financial Crisis. Finance a Uver: Czech Journal of Economics and Finance, 59(6): 507-521.

Goetzmann, W. N. - Li, L. - Rouwenhorst, K. G. (2005): Long-Term Global Market Correlations. Journal of Business, 78(1): 1-38.

Hanousek, J. - Filer, R. K. (2000): The Relationship between Economic Factors and Equity Markets in Central Europe. Economics of Transition, 8(3): 623-638.

Hong, Y. - Tu, J. - Zhou, G. (2007): Asymmetries in Stock Returns: Statistical Tests and Economic Evaluation. Review of Financial Studies, 20(5): 1547-1578.

Kizys, R. - Pierdzioch, C. (2011): The Financial Crisis and the Stock Markets of the CEE Countries. Finance a Uver: Czech Journal of Economics and Finance, 61(2): 153-172.

Kocsis, Z. (2014): Global, Regional and Country-Specific Components of Financial Market Indicators. Acta Oeconomica, 64(Special Issue): 81-110.

Konopczak, K. - Marczewski, K. (2011): Why So Different from Other CEECs - Poland's Cyclical Divergence from the Euro Area during the Recent Financial Crisis. Bank i Kredyt, 42(2): 7-30.

Lee, J. S. - Kuo, C. T. - Yen, P. H. (2011): Market States and Initial Returns: Evidence from Taiwanese IPOs. Emerging Markets Finance \& Trade, 47(2): 6-20.

Ljung, G. - Box, G. E. P. (1978): On a Measure of Lack of Fit in Time Series Models. Biometrika, 65(2): 67-72.

Longin, F. - Solnik, B. (2001): Extreme Correlation of International Equity Markets. Journal of Finance, 56(2): 649-676.

Lunde, A. - Timmermann, A. (2000): Duration Dependence in Stock Prices: An Analysis of Bull and Bear Markets. University of California, San Diego.

Maheu, J. M. - McCurdy, T. H. (2000): Identifying Bull and Bear Markets in Stock Returns. Journal of Business \& Economic Statistics, 18(1): 100-112.

Marer, P. (2010): The Global Economic Crises: Impact on Eastern Europe. Acta Oeconomica, 60(1): 3-33.

Merler, S. - Pisani-Ferry, J. (2012): Sudden Stops in the Euro Area. Breugel Policy Contribution, 2012/06, March: 1-16.

Mishkin, F. S. (2011): Over the Cliff: From the Subprime to the Global Financial Crisis. Journal of Economic Perspectives, 25(1): 49-70.

Mun, M. - Brooks, R. (2012): The Roles of News and Volatility in Stock Market Correlations during the Global Financial Crisis. Emerging Markets Review, 13(1):1-7.

Olbrys, J. - Majewska, E. (2013): Granger Causality Analysis of the CEE Stock Markets Including Nonsynchronous Trading Effects. Argumenta Oeconomica, 31(2): 151-172.

Olbrys, J. - Majewska, E. (2014): Quantitative Identification of Crisis Periods on the Major European Stock Markets. Pensee Journal, 76(1): 254-260.

Pagan, A. R. - Sossounov, K. A. (2003): A Simple Framework for Analysing Bull and Bear Markets. Journal of Applied Econometrics, 18(1): 23-46.

Pisani-Ferry, J. - Sapir, A. (2010): Banking Crisis Management in the EU: An Early Assessment. Economic Policy, 25(62): 341-373.

Rigobon, R. (2002): Contagion: How to Measure it? In: Edwards, S. - Frankel, J.A. (eds): Preventing Currency Crises in Emerging Markets. Chicago: University of Chicago Press.

Smith, G. (2009): Martingales in European Emerging Stock Markets: Size, Liquidity and Market Quality. The European Journal of Finance, 15(3): 249-262.

Southall, T. (2008): European Financial Markets. The Effects of European Union Membership and Central and Eastern European Equity Markets. Heidelberg: Physica Verlag.

Tsay, R. S. (2010): Analysis of Financial Time Series. New York: John Wiley \& Sons Ltd. 